\title{
Impact of Daylight Exposure on Sleep Time and Quality of Elementary School Children
}

\author{
M. Boubekri*, J. Lee, K. Bub and K. Curry \\ University of Illinois
}

\begin{tabular}{|c|c|}
\hline ARTICLE INFO & ABSTRACT \\
\hline $\begin{array}{l}\text { Keywords: } \\
\text { Children } \\
\text { Classroom } \\
\text { Daylighting } \\
\text { Light spectrum } \\
\text { Light exposure } \\
\text { Sleep quality }\end{array}$ & $\begin{array}{l}\text { The purpose of this study was to examine how daylight exposure affects the } \\
\text { health and well-being of elementary school children. Sleep actigraphy data } \\
\text { were the main dependent variables in this study. Independent variables were } \\
\text { total light and daylight levels elementary school children were exposed to } \\
\text { inside their classrooms as well as outside. Participants were composed of } \\
\text { elementary school children ( } 46 \% \text { female, mean age }=7.27 \text { years, } 33 \% \\
\text { African American) attending a rural and urban schools in the mid-west, } \\
\text { each set of children divided into groups according to classroom orientation. } \\
\text { Eighty participants in total wore light-sensor equipped actiwatches for one- } \\
\text { week to measure sleep quality and exposure to ambient light levels. To } \\
\text { assess light levels students were exposed to beyond the one-week of } \\
\text { actigraphy measurements, data logging light meters were placed in various } \\
\text { locations within the classrooms for an entire semester. Our results seem to } \\
\text { indicate that studying in daylit classroom spaces would lead to higher sleep } \\
\text { time and quality compared to those who receive little or no daylight. We } \\
\text { measured differences as large as } 36 \text { minutes. We recommend, therefore, } \\
\text { that classroom design need to pay attention to the daily daylight exposures } \\
\text { elementary school children are receiving. }\end{array}$ \\
\hline
\end{tabular}

\section{Introduction}

Light is an essential ingredient for human health. Light is also the main catalyst for circadian rhythm regulation. Research has shown that the intensity, duration and timing of light exposure offer potent signals to our brain to regulate circadian physiology and behavior (Roenneberg, Kantermann, Juda, Vetter, \& Allebrandt, 2013; Vetter, Juda, Lang, Wojtysiak, \& Roenneberg, 2011). For example, sleep quantity and sleep quality are significantly higher in summer, when light exposure is greater, than in the winter, when there is less daylight (Figueiro \& Rea, 2014). In contrast, improper circadian rhythm entrainment is associated with sleep disturbance and other health problems such as chronic or seasonal depression. Although both natural and artificial bright light, particularly in the morning, can significantly improve health outcomes [Rosenthal, Sack et al., 1985; Lam, Levitt \& Levitan et al., 2006; Clickman, Byrne et al., 2006), the light levels needed to treat circadian rhythm disorders are too high to be supplied solely by typical electrical lighting systems (which typically supply 300-500 lux relative to the 1,00010,000 lux supplied by natural daylight) found inside office and school buildings due to limits on energy consumption set by energy codes (ASHRAE, 2013; California Building Standard Code, 2013; IESNA, 2011). As a result, building occupants are generally exposed to light levels of illumination below what is needed to regulate circadian rhythms and contribute to general good health. Natural daylight, however, may help supply the light levels needed for proper circadian rhythm regulation. Sleep is critical for adequate development and optimal functioning (Blunden, Lushington, Lorenzen, Martin, \& Kennedy, 2005; Buckhalt, El-Sheikh, \& Keller, 2007; Sadeh, Gruber, \& Raviv, 2003) but national surveys have shown that children and adults

* Corresponding Author E-Mail Address: mboubekri2@gmail.com 
are sleeping much less than is recommended (Owens, Spirito, McGuin, \& Nobile, 2000). Indeed, sleep disruptions occur in $20 \%$ to $40 \%$ of school-aged children (Singh \& Kenney, 2013) and more than $35 \%$ of adults report that they regularly sleep fewer than seven hours a night (CDC, 2011). Sleep disruptions are also occurring at increasingly younger ages (Bates, Viken, Alexander, Beyers, \& Stockton, 2002). Reducing sleep by as little as one hour has substantial negative consequences on learning, memory consolidation, attention, and emotionregulation (El-sheikh, Bub, Buckhalt, \& Kelly, 2013; Sadeh, 2007). Child health is also associated with sleep. For example, sleep disturbance and delayed sleep predicted obesity among otherwise healthy children (Jarrin, McGrath, \& Drake, 2013). Similarly, insomnia is associated with increased morning and evening cortisol levels (Fernandez-Mendoza et al., 2014).

Using a diverse sample of elementary school-aged children and their teachers, one goal of the proposed project is to investigate the independent effects of natural light (distinct from artificial light) exposure during the school day on multiple aspects of sleep, including duration, quality, and consistency.

\section{Research Approach}

We have recruited a total of 80 students from two different school districts. Students grades ranged from $1^{\text {st }}$ to $3^{\text {rd }}$ grade. Our sample size was comprised of $46 \%$ female $54 \%$ males, with a mean age of 7.27 years. The sample was composed of $64 \%$ Whites and $33 \%$ African Americans. The 80 participants in total wore light-sensor equipped actiwatches for one-week to measure sleep quality and exposure to ambient light levels.

To assess the light levels that students were exposed to beyond the one-week period of actigraphy measurements, data logging light meters were placed in various locations within the classrooms for an entire semester, which allowed us to measure the average light levels students were exposed to within their respective classrooms for much longer periods. Level and duration of light exposure are assessed using Hobo data loggers (HDL). These can measure light levels at programmable frequencies (e.g., every 15 minutes for 1 day to several months). Each classroom has been equipped with 5 HDLs placed at various locations and will be programmed to take light measurements every 15 minutes for the entire fall and spring semesters. Daylight exposure in the classroom is calculated by subtracting total ambient electric light levels inside the classroom (measured at night) from the total ambient light levels measured during the day that include both daylight and electric light.

For the current study, we have used the Mean Hourly Daylight Illuminance (MHDI) metric. This is a daylighting metric that represents the sum of all hourly average light levels measured between 8:00 AM and 3:00 PM. The MHDI will be calculated over the two semesters for each cohort. Finally, the actiwatches are equipped with photosensors that measure ambient light levels when students and teachers are outside the classroom

Objective measures of sleep quantity, quality, and consistency will be collected over a 7-day period from children and teachers using Motionlogger Watches from Ambulatory Monitoring. Based on coding recommendations for young children (Acebo et al., 1999), we have extracted sleep onset time, sleep offset time, true sleep time, sleep latency, sleep efficiency, and movement and fragmentation. Actigraphic measures of sleep have good reliability and have been validated against polysomnography with agreements ranging from $85 \%$ to $90 \%$ (Sadeh et al., 1994; 1995).

\section{Data Analysis}

3.A. Light Exposure 

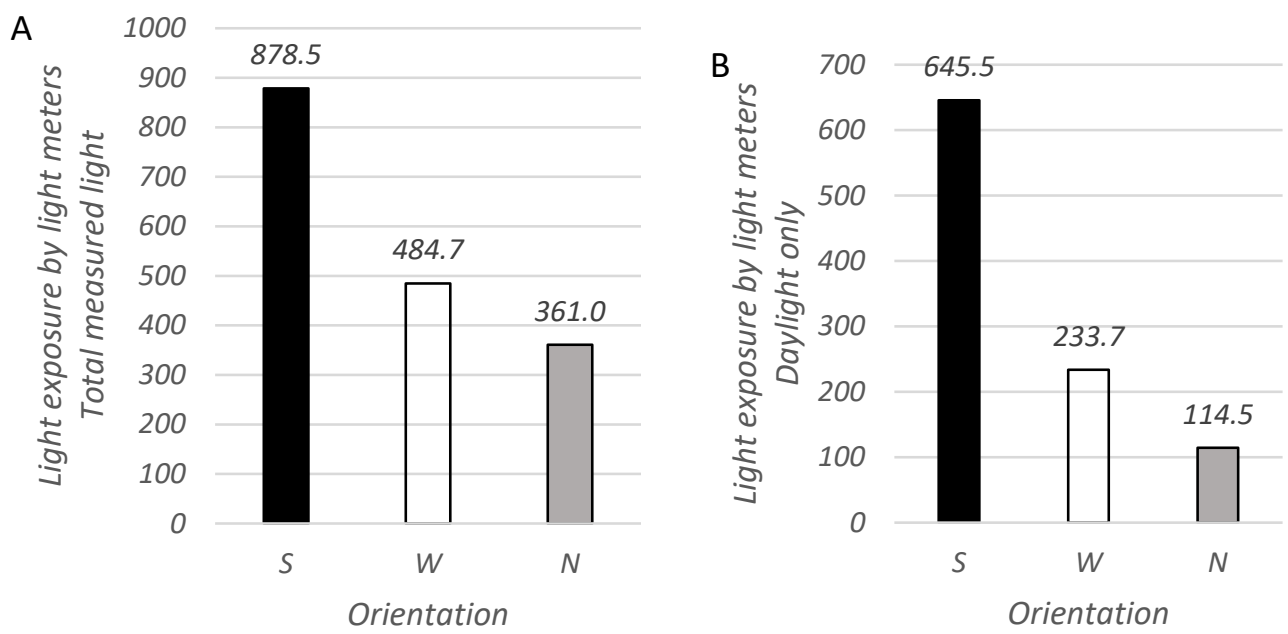

Figure $1 a \& b$. Class orientation and total light (a) vs. daylight (b) exposure measured with the data loggers.

Figures 1 a \& b illustrate light levels measured by the data loggers in classrooms of School District 1, Figure 1a represents total daily ambient light in the classrooms with 3 different oorientations (South, West and North) and figure $1 \mathrm{~b}$ represents average daylight levels only in those classrooms during an 8:00 AM-3:00 PM schedule. Students in the south facing classroom received 393.8 lux (44.8\%) and 517.5 lux (58.9\%) in total ambient light more than those in the west and north classrooms respectively. In terms of daylight exposure, students in the south classrooms received 411.8 lux (63.7\%) and 531 lux (82.26\%) more than students in the west and north classrooms respectively.

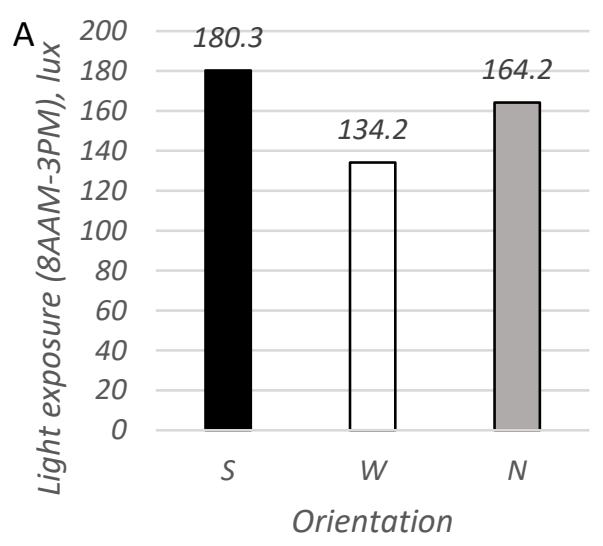

(a)

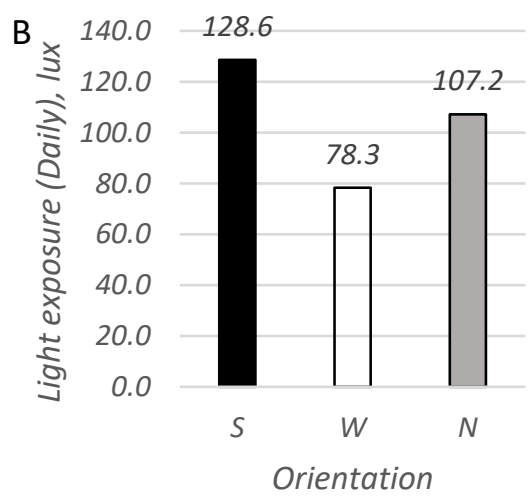

(b)

Figure $2 a \& b$. Class orientation and total light during class time (a) vs. daily (b) exposure measured with actiwatches.

Figures $2 \mathrm{a} \& \mathrm{~b}$ show the average light exposure levels measured by the built-in photosensors in the actiwatches worn by students inside the classrooms (a) and throughtout the day (b) during the 5 days that students wore the actiwatches. According to actiwatch measurements, students in the south facing classroom received more light during classroom time (8:00 AM - 3:00 PM) as well as throughout the day. During classtime, students students in the south classroom received $25.5 \%$ more light than their western counterparts and $8.9 \%$ more than those in the north classroom. In terms of daily light exposure, also measured by the actiwatches, the students in the south classrooms also received the highest levels of total light, $39.1 \%$ more than those in the west classroom and $16.6 \%$ more than those in the north classroom. It would be 
difficult to account for differences in light exposure outside the classroom given the fact that we are dealing with 5 to 7 years old children. However, we notice of light exposure inside and outside the classrooms follows the same pattern given classroom orientation. This means that exposure to light levels inside the classroom dictates to a large extent the overall light exposure these kids are getting on a daily basis in particularly during the winter season when days are short. Moreover, we also noticed a very large difference between the light measurements by the stationary photosensors placed in various locations inside the classroom and the data obtained by the actiwatches worn by the students (Fig. 1 a, Fig. 2 a). Light levels measured by stationary photosensors are at time 7 or 8 times higher than those measured by the actiwatches. This indicates that light levels measured with the stattionary light meters maybe more reliable than the measurements with the built-in light sensors in the actiwatches worn by the children.

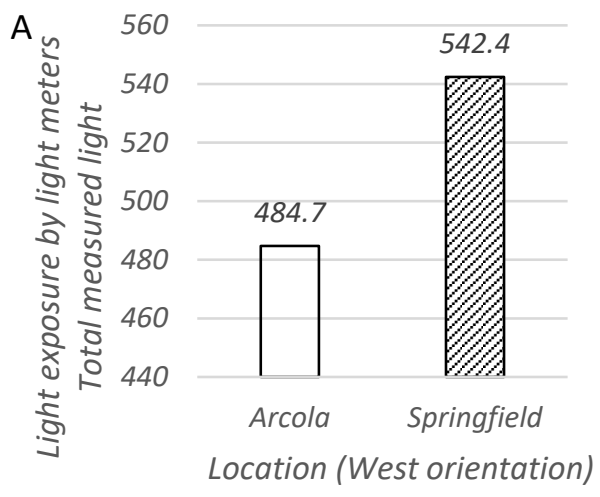

(a)

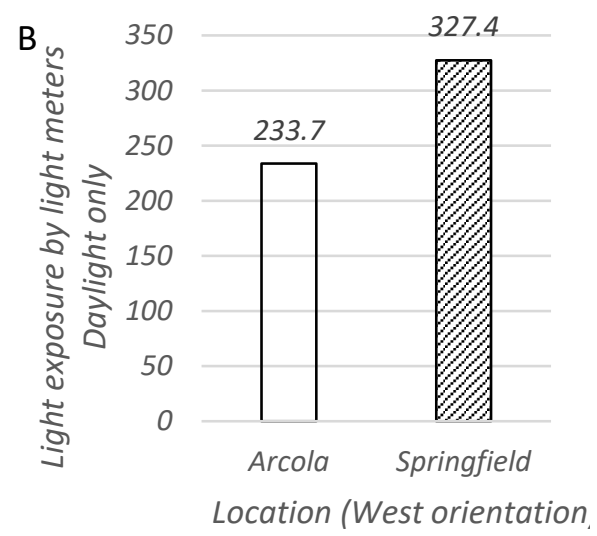

(b)

Figure $3 a \& b$. Comparison of light exposures from the classroom light meters between west classrooms in Arcola, IL (District 1) and Springfield, IL (District 2)

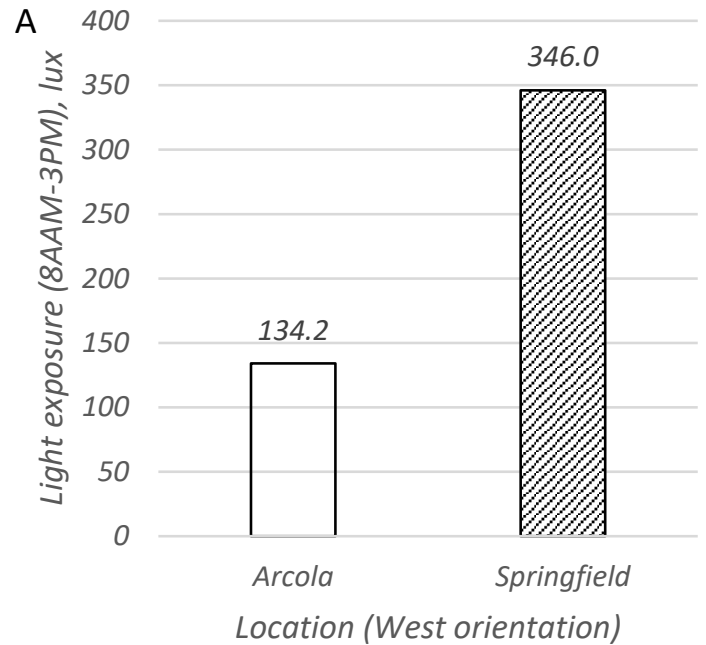

(a)

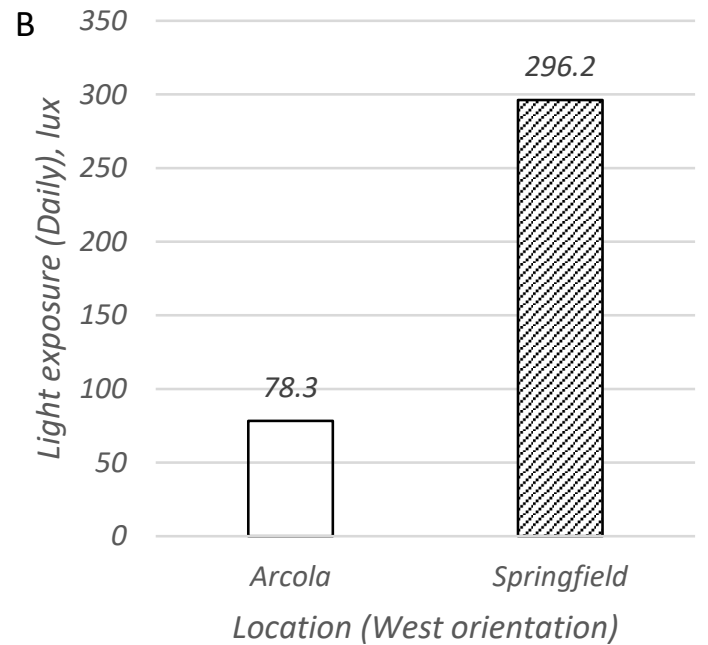

(b)

Figure $4 \mathrm{a} \& \mathrm{~b}$. Comparison of light exposures during class time and daily exposure from the actiwatches between west classrooms in Arcola, IL (District 1) and Springfield, IL (District 2).

Figures 3 a \& b compare the average total light levels (figure $3 a$ ) and average daylight levels (figure $3 b$ ) students are exposed to during school hours in two west-facing classrooms in two different school districts in Illinois. We note that students in District 2 (Springfield, Illinois)) received 57.7 lux $(\sim 43 \%)$ more total light and 93.7 lux $(\sim 40 \%)$ more daylight than those in District 1 (Arcola, Illinois). Actiwatch light measurements showed given similar west 
orientation, students in District 2 in received 217.9 lux ( 278.2\%) more in total light exposure than those in District 1 (Figures $4 \mathrm{a} \& \mathrm{~b}$ ). It is worth noting that architecture of classrooms in District 1 and 2 have largely different amount of daylight due to different architectures. Classrooms in District 1 had much smaller windows admitting almost insignificant amount of daylight (Figure 5), whereas classrooms in Springfield were equipped with larger windows and more daylight (Figure 6).

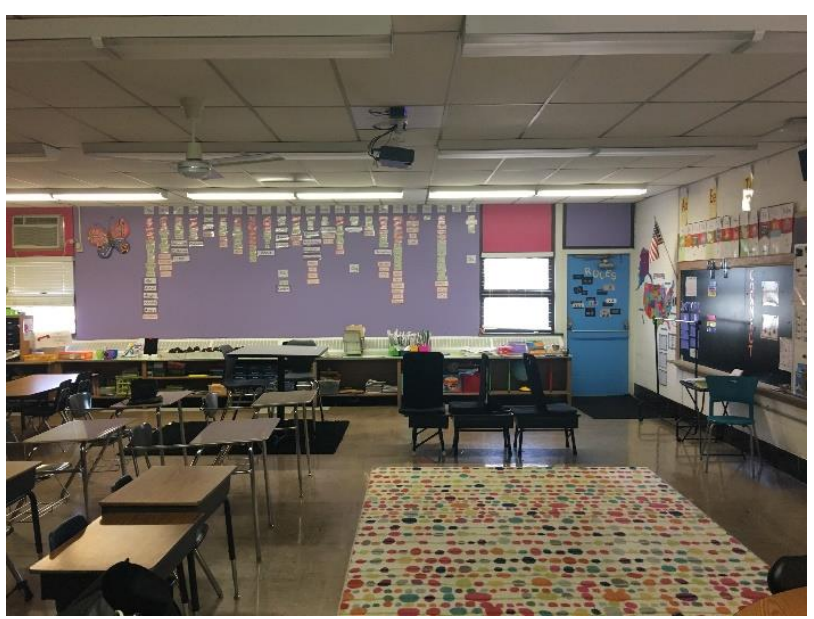

Figure 5. Typical classroom in Arcola School (District 1).

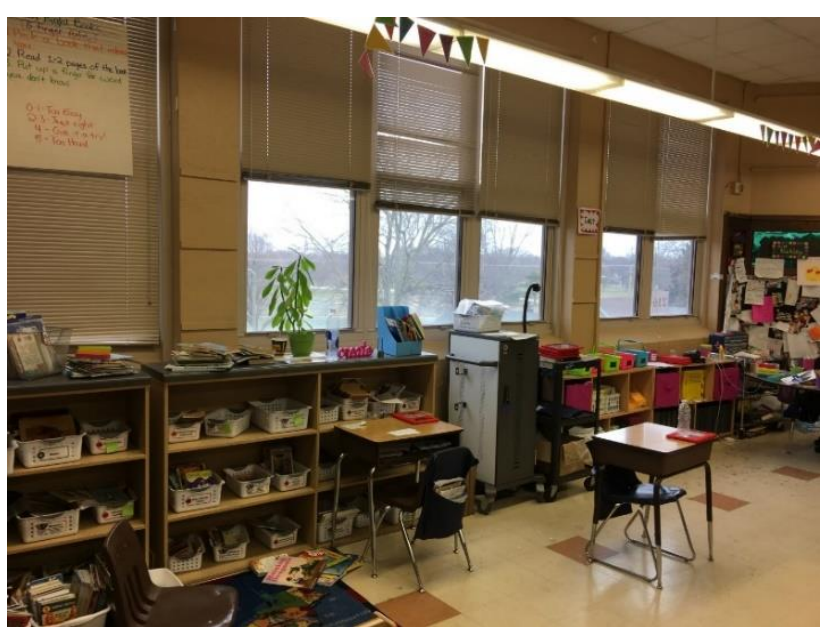

Figure 6. Typical classroom in Springfield School (District 2)

\section{B. Sleep Quality}

Figures 7 a \& b indicate the daily average sleep time and sleep efficiency measured by the actiwatches for students in the south, west and north classrooms in district 1 . We observe that students in the south classrooms with the highest light levels slept 11.8 minutes per day more than those in the north classroom and nearly 37 minutes more than those in the western classrooms that had the lowest light levels in the classroom overall. Sleep efficiency was not, however, noticeably different between the 3 classrooms. 


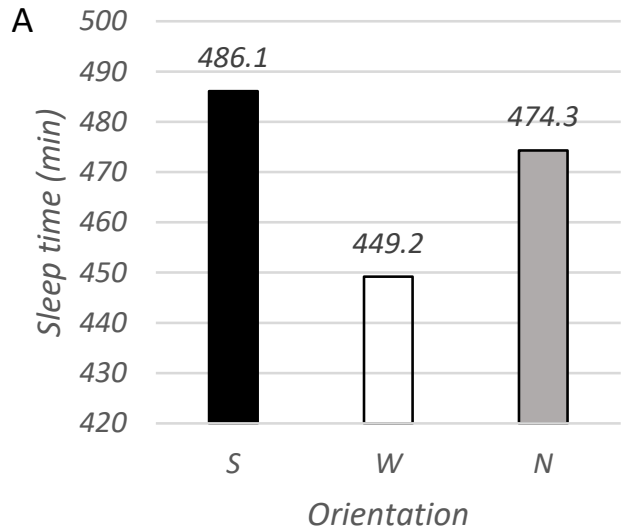

(a)

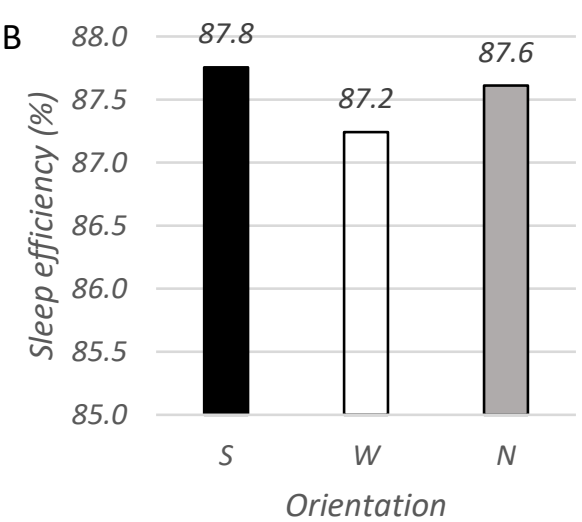

(b)

Figure $7 a \& b$. Class orientation and sleep in Arcola, IL. School District 1

When comparing sleep time between classrooms having the same orientation (in this case west) in the two districts $1 \& 2$, we notice that sleep time follows the same trend as the exposure to light in the classroom. Students in District 2 slept on average 30.3 minutes per night more than those in District 1 (Figure 8a). Sleep efficiency was marginally the same however (Fig. 8b).

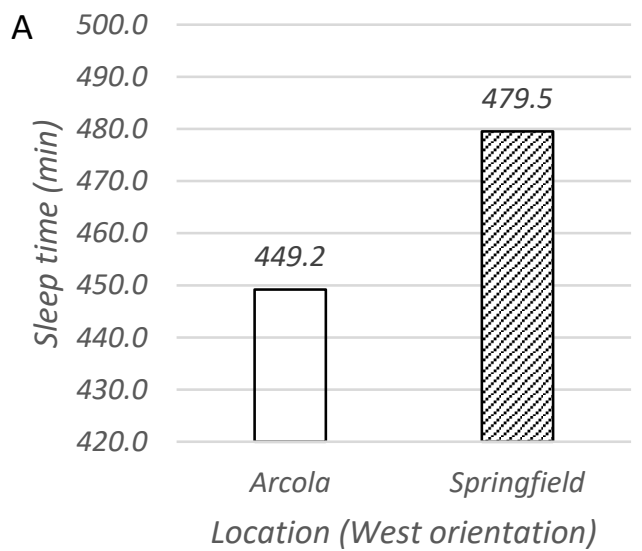

(a)

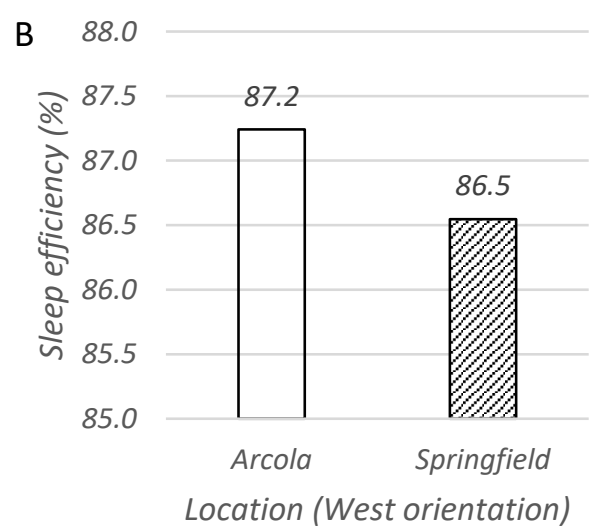

(b)

Figure $8 a \& b$. Comparison of sleep time and sleep efficiency between two west facing classrooms in Arcola, IL (District 1) and Springfield, IL (District 2).

\section{Interpretation and Conclusion}

Our data indicates that the students who were exposed to the significantly highest levels of light in the classroom during class time had the highest number of minutes of sleep per night. Our data indicate students exposed to highest total light levels as well as the highest daylight levels in the classroom, either due to classroom orientation for the same classroom fenestration design or caused by the fact that students benefited by the presence of larger windows, slept the longest. In our case, the sleep time difference was as large as 37 minutes per night between students in the same school facing south and those with classrooms facing west. While comparing students with the same western orientation in two different districts, the difference in sleep time was around 30 minutes with those with higher light exposure slept the longest. We also observed that light levels in the classrooms measured by stationary data loggers and those measured by actiwatches were significantly different, with the actiwatch light levels 
being much lower. This may be caused by the fact that actiwatches may have been covered by the children's clothing which makes them not reliable.

We conclude, therefore, there is strong possibility that exposure to higher levels in the classroom by elementary school students lead to longer sleep time.

\section{References}

Acebo, C. Sadeh, A. Seifer, R., Tzischinsky, O.- Estimating sleep patterns with activity monitoring in children and adolescents: how many nights are necessary for reliable measures? Sleep 22, 95-103, 1999

Buckhalt JA, El-Sheikh M, Keller P. Children's sleep and cognitive functioning: Race and socioeconomic status as moderators of effects. Child Development. 2007;78:213-231. [PubMed] [Google Scholar]

Blunden S, Lushington K, Lorenzen B, Martin J, Kennedy D. Neuropsychological and psychosocial function in children with a history of snoring or behavioral sleep problems. Journal of Pediatrics. 2005;146(6):780-786.

Bates, J. E., Viken, R. J., Alexander, D. B., Beyers, J., \& Stockton, L. (2002). Sleep and adjustment in preschool children: Sleep diary reports by mothers; Child Development January 2002, 73(1):62-74 .

El-Sheikh, M, Bub K.L, Kelly R.J, Buckhalt, JA. Children's sleep and adjustment: a residualized change analysis. Dev Psychol. 2013 Aug;49(8):1591-601. doi: 10.1037/a0030223. Epub 2012 Oct 1.

Fernandez-Mendoza J, Vgontzas AN, Calhoun SL, Vgontzas A, Tsaoussoglou M, Gaines J, Liao D, Chrousos GP, Bixler EO. Insomnia symptoms, objective sleep duration and hypothalamic-pituitary-adrenal activity in children., Eur J Clin Invest. 2014 May;44(5):493500

Jarrin, D.C, McGrath J.J, Drake C.L. Beyond sleep duration: distinct sleep dimensions are associated with obesity in children and adolescents. Int J Obes (Lond). 2013 Apr;37(4):5528. doi: 10.1038/ijo.2013.4. Epub 2013 Feb 19.

Owens J, Spirito A, Marcotte A, McGuinn M, Berkelhammer L. Neuropsychological and Behavioral Correlates of Obstructive Sleep Apnea Syndrome in Children: A Preliminary Study. Sleep \& Breathing. 2000;4(2):67-78

Roenneberg T, Kantermann T, Juda M, Vetter C, Allebrandt K.V. Light and the human circadian clock.; Handb Exp Pharmacol. 2013;(217):311-31. doi: 10.1007/978-3-64225950-0_13.

Sadeh A , Sharkey K. , and Carskadon MA (1994) Activity-based sleep-wake identification: An empirical test of methodological issues. Sleep 17:201-207.

Sadeh A1, Hauri PJ, Kripke DF, Lavie P. The role of actigraphy in the evaluation of sleep disorders. Sleep. 1995 May;18(4):288-302.

Sadeh, A., Gruber, R., \& Raviv, A. The Effects of Sleep Restriction and Extension on SchoolAge Children: What a Difference an Hour Makes. Child Development 2003; 74(2):444-55.

Singh, GK and Kenney, MK. Rising Prevalence and Neighborhood, Social, and Behavioral Determinants of Sleep Problems in US Children and Adolescents, 2003-2012. Sleep Disord. 2013;2013:394320. doi: 10.1155/2013/394320. Epub 2013 May 30. 
Vetter C, Juda M, Lang D, Wojtysiak A, Roenneberg T. Blue-enriched office light competes with natural light as a zeitgeber; Scand J Work Environ Health. 2011 Sep;37(5):437-45. doi: 10.5271/sjweh.3144. Epub 2011 Jan 19.

Figueiro, M.G., Rea, M.S. Office lighting and personal light exposures in two seasons: Impact on sleep and mood; Lighting Res \& Tech., 2016. 48(3), 265-265.

Rosenthal NE, Sack DA, Gillin JC, et al. Antidepressant effects of light in seasonal affective disorder Am J Psychiatry 1985; 142: 163-170.

Lam, R.W., Levitt, A.J., Levitan, R.D., Michalak, E.E. Efficacy of bright light treatment, fluoxetine, and the combination in patients with nonseasonal major depressive disorder: a randomized clinical trial - JAMA Psychiatry. 2016;73(1):56-63.

Glickman, G., Byrne, B., Pineda, C., Hauck, W.W., Brainard, G.C., Light Therapy for Seasonal Affective Disorder with Blue Narrow-Band Light-Emitting Diodes (LEDs), Biol. Psych., March 15, 2006. 59(6), 502-507.

IESNA. LM-83-12 IES Spatial Daylight Autonomy (sDA) and Annual Sunlight Exposure (ASE); Iesna Lighting Meas: New York, NY, USA, 2012. 